\title{
A Retrospective Study of Directed Blood Donations in the Kasungu District of Malawi
}

\author{
David S. Chung1, Fenjun Shen², Sumin Lee3, Taekwon Kong ${ }^{4}$ Jonathan Ko5, \\ Jin Young Choe ${ }^{6}$, Sang Min Lee ${ }^{7}$, George Talama ${ }^{8}$ \\ ${ }^{1}$ School of Medicine, University of Virginia, Charlottesville, VA, USA \\ ${ }^{2}$ Department of Chemistry and Biochemistry, UC Santa Barbara, Santa Barbara, CA, USA \\ ${ }^{3}$ Department of Human Biology, Michigan State University, East Lansing, MI, USA \\ ${ }^{4}$ Department of Chemistry, Washington University, St. Louis, MO, USA \\ ${ }^{5}$ School of Arts and Sciences, NYU, Yew York, NY, USA \\ ${ }^{6}$ Seoul International School, Seongnam, South Korea \\ ${ }^{7}$ La Canada High School, La Canada, CA, USA \\ ${ }^{8}$ Kasungu District Hospital, Kasungu, Malawi \\ Email: paulschung08@gmail.com
}

How to cite this paper: Chung, D.S., Shen, F., Lee, S., Kong, T., Ko, J., Choe, J.Y., Lee, S.M. and Talama, G. (2018) A Retrospective Study of Directed Blood Donations in the Kasungu District of Malawi. Open Journal of Blood Diseases, 8, 74-82.

https://doi.org/10.4236/ojbd.2018.84008

Received: February 22, 2018

Accepted: October 19, 2018

Published: October 22, 2018

Copyright (c) 2018 by authors and Scientific Research Publishing Inc. This work is licensed under the Creative Commons Attribution International License (CC BY 4.0).

http://creativecommons.org/licenses/by/4.0/

\section{c) (i) Open Access}

\begin{abstract}
Since the discovery of blood circulation and transfusion, there has been an insatiable demand for voluntary blood donations throughout the world. However, gathering blood donors has never been easy because eligible donors constitute only a fraction of the general population and are often reluctant to donate. This is especially challenging in underprivileged countries of sub-Saharan Africa such as Malawi whose nationally run blood transfusion service struggles to maintain hospital blood banks. As a result, hospitals turn to their local communities for directed donations. A retrospective analysis from January 2014 to June 2016 of directed blood donor data from two hospitals in the Kasungu District of Malawi was conducted. The analysis of 2134 donations was carried out with respect to sex, age, hemoglobin concentration, blood group, and presence of transfusion-transmissible infections. On average, donors were 30 years of age and predominately male. Blood group $\mathrm{O}+$ constituted more than half of all directed blood donations. Ultimately, about one third of donations were unable to be utilized for transfusion.
\end{abstract}

\section{Keywords}

Blood Type, Blood Donor Data, Malawi

\section{Introduction}

Since the discovery of blood circulation and transfusion, there has been an insa- 
tiable demand for voluntary blood donations to supply blood banks throughout the world. Because blood serves as one of the most vital resources in healthcare, many international guidelines and ethics for blood transfusion have been established to ensure safety. Collecting blood from regular voluntary, non-remunerated blood donors is internationally advocated to be the safest method of blood transfusion [1].

Nonetheless, blood transfusion services face a number of challenges in gathering voluntary donors, who supply hospital blood banks with mainly allogeneic donations. Furthermore, donated blood must be tested for the presence of transfusion-transmissible infections (TTIs), which include human immunodeficiency virus (HIV), viral hepatitis A and B (HBV, HCV), syphilis, and malaria [2]. These challenges are magnified in Sub-Saharan countries of Africa where there are a lack of resources and an overabundant presence of TTIs [3].

Located in Central Africa, Malawi is considered to be one of the most destitute countries in the world [4]. Malawian hospital blood banks often run dry, and their communities struggle to access safe and adequate blood. Malawi Blood Transfusion Service (MBTS), Malawi's nationally coordinated blood transfusion service, lacks the funds to sufficiently supply and maintain hospital blood banks throughout the country. As a result, hospitals frequently take matters into their own hands and turn to additional directed donations, when an individual-often a friend or family relative-donates blood to a specific person who may need immediate transfusion [5]. These directed donations are received directly by the hospital and independently of MBTS. Due to the urgency, blood that is received from directed donations is tested less extensively in hospital facilities than allogeneic donations at MBTS's testing center.

The aim of this study is to explore directed blood donor demographics by retrospectively analyzing directed blood donations from the Kasungu District of Malawi to better understand and bring awareness of the depth of issues surrounding blood transfusion in Malawi.

\section{Materials and Methods}

In Malawi, the legal age for acceptable blood donation ranges from 16 to 65 years. To follow national guidelines for safe blood transfusion, hospitals utilize a series of rapid tests to identify $\mathrm{ABO}$ and $\mathrm{RhD}$ grouping, TTIs, and compatibility testing. $\mathrm{ABO}$ grouping was determined using standardized antisera to test for red blood cells. The presence of $\mathrm{RhD}$ factor was determined using standardized antisera to test for D red cell antigen. Rapid tests for HIV screened for antibody and antigens. Rapid tests for HCV and syphilis screened for Hepatitis $\mathrm{C}$ and syphilis antibodies. Rapid tests for HBV screened for Hepatitis B surface antigen. Rapid tests for malaria screened for malaria parasites [6]. Once blood samples were approved for safety and compatibility, they were quickly used for directed donor transfusion.

Archived data of directed blood donations received at St. Andrew's Hospital and Kasungu District Hospital, 2 of 3 public hospitals in the Kasungu district of 
Malawi, were reproduced electronically and retrospectively reviewed. The directed blood donation data received from St. Andrew's Hospital consists of 1573 blood donations and spans from January 2014 to June 2016. These data were compared to and used alongside 433 directed blood donations received at Kasungu District Hospital in April 2016. Blood donor sex, age, hemoglobin content $(\mathrm{g} / \mathrm{dL}), \mathrm{ABO}$ and $\mathrm{RhD}$ blood group, and presence of TTIs were extracted from hospital medical records and reproduced using Microsoft Excel to be stored and analyzed. Data was processed electronically using Microsoft Excel functions. The results are summarized and presented in tables and graphs. Furthermore, interpretations, discussions, and conclusions of results are provided. Ethical approval and permission to conduct the study was received from St. Andrew's Hospital and Kasungu District Hospital.

\section{Results}

We evaluated 2134 directed blood donations that were provided by volunteers who donated to St. Andrew's Health and Kasungu District Hospital independently of MBTS. 1689 donations were received at St. Andrew's Hospital from January 2014 to June 2016, and 445 donations were received at Kasungu District Hospital during April 2016. Unfortunately, not all donations have complete records on every parameter. As a result, depending on the analysis conducted, some cases were unable to be utilized due to a lack of sufficient data.

Table 1 details the distribution of sex groups among directed blood donors by hospital. In both hospitals, males constituted an overwhelming majority of directed blood donations. However, Kasungu District Hospital reports greater relative frequencies for both male and female sex groups. Males led by a slight margin while females were ahead by greater. This is because while St. Andrew's Hospital failed to record donor sex on about $9 \%$ of their donations, there were only two instances in which Kasungu District Hospital was only unable to record donor sex. Figure 1 provides a pie graph representation of sex group distribution among total donors.

Table 1. Distribution of sex groups among directed blood donors $(\mathrm{n}=2134)$.

\begin{tabular}{cccc}
\hline Hospital & Sex Group & Absolute Frequency (n) & Relative Frequency (\%) \\
\hline St. Andrew's & Male & 1263 & 74.8 \\
Hospital & Female & 276 & 16.3 \\
& N/A & 150 & 8.9 \\
& Male & 334 & 75.1 \\
Kasungu District & Female & 109 & 24.5 \\
Hospital & N/A & 2 & 0.4 \\
& Male & 1597 & 74.8 \\
& Female & 385 & 18.0 \\
Combined & N/A & 152 & 7.1 \\
\hline
\end{tabular}




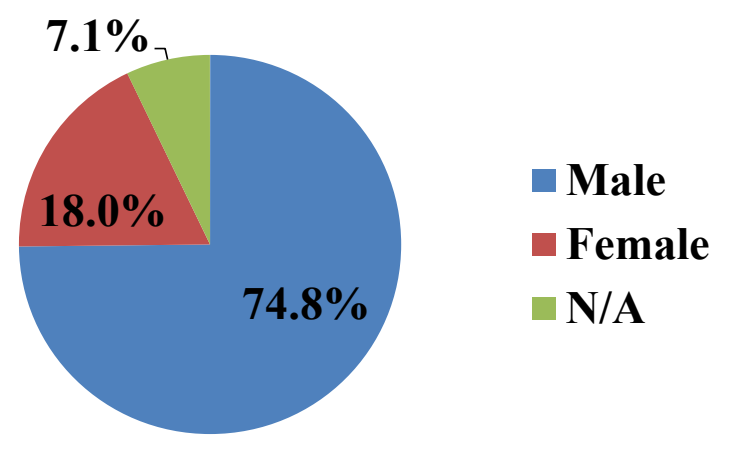

Figure 1. Sex group distribution among total donations.

Additionally, $90.3 \%$ of total directed blood donations (2134) were analyzed to determine average age by sex, and $73.0 \%$ of cases were analyzed to determine average hemoglobin concentration $(\mathrm{g} / \mathrm{dL})$ by sex. Nonetheless, both hospitals show similar results concerning average donor age and hemoglobin concentration. Average donor age was largely consistent for both sexes at $30-31$ years of age. Males of both hospitals averaged $15.1 \mathrm{~g} / \mathrm{dL}$ in hemoglobin concentration; females in St. Andrew's Hospital and Kasungu District Hospital differed slightly, with averages of $13.4 \mathrm{~g} / \mathrm{dL}$ and $13.7 \mathrm{~g} / \mathrm{dL}$ respectively. Furthermore, due to physiological differences between sexes, the normal range for male hemoglobin concentration is higher than that of females. Table 2 depicts the average age of male and female directed blood donors by hospital, and Table 3 shows the average hemoglobin concentrations of male and female directed blood donors.

We evaluated 2082 cases to determine $\mathrm{ABO}$ and $\mathrm{RhD}$ blood group distribution among directed blood donations. The data yield 8 distinct blood groups: $\mathrm{A}+, \mathrm{A}-, \mathrm{B}+, \mathrm{B}-, \mathrm{AB}+, \mathrm{AB}-, \mathrm{O}+$, and $\mathrm{O}_{-}$. The + and - symbols indicate the presence or absence of the $\mathrm{RhD}$ factor respectively. The relative frequencies of blood group $\mathrm{A}, \mathrm{B}, \mathrm{AB}$, and $\mathrm{O}$ were $18.4 \%, 20.1 \%, 3.1 \%$, and $58.3 \%$ respectively. Blood group $\mathrm{O}$ was the most commonly found $\mathrm{ABO}$ blood group, and blood group ABwas the least. An overwhelming majority (80.3\%) of all donations contained the $\mathrm{RhD}$ factor. The data were consistent between both hospitals. Table 4 details the raw distribution of blood groups by hospital. Figure 2 provides a graphical representation of the relative distribution of blood groups by hospital.

Of 1977 donations evaluated, only $64.8 \%$ were determined to be safe for transfusion. These rates were consistent between male and females. Table 5 depicts the number of accepted and rejected donations by hospital and sex group as well as their acceptance rates. Eligibility is largely determined by the detection of transfusion-transmissible infections (TTIs), which include HIV, hepatitis B and C, syphilis, and malaria. Among 1982 donations, there were 410 positive tests for TTIs. Malaria constituted the majority (72.2\%) of the positive tests. Due to the possibility of comorbidity, some donations may account for multiple positive tests. Table 6 shows the number of positive, negative, and not done (ND) cases of TTIs among directed blood donations. Figure 3 provides a graphical representation of the TTI incidence. 
Blood Group Distribution

$\|\mathrm{A}+\| \mathrm{A}-\square \mathrm{B}+\square \mathrm{B}-\|\mathrm{AB}+\| \mathrm{AB}-\square \mathrm{O}+\square \mathrm{O}-$

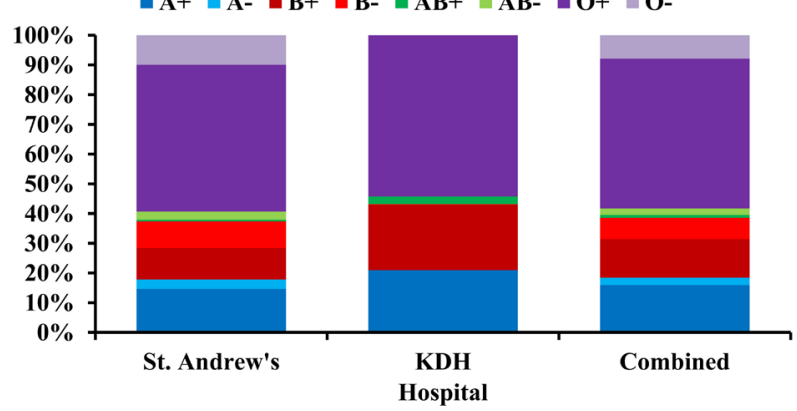

Figure 2. Relative blood group distribution by hospital.

TTI incidence among blood donations

घ St. Andrew's $\square$ KDH $\square$ Combined

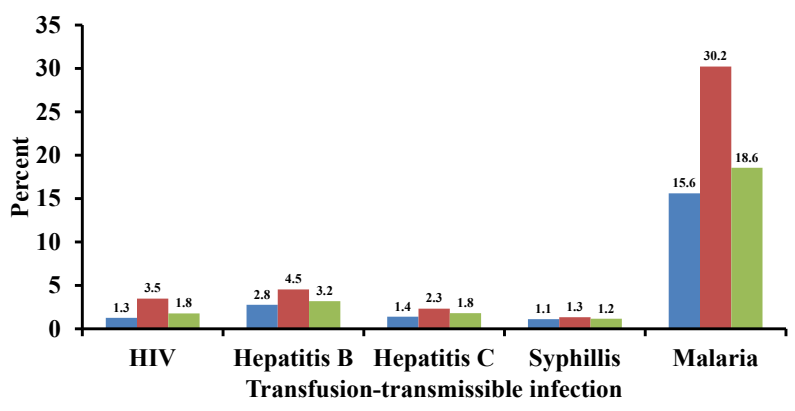

Figure 3. TTI incidence among blood donations by hospital.

Table 2. Average age in years of male and female blood donors $(n=1926)$.

\begin{tabular}{ccccc}
\hline Hospital & Sex Group & Applicable Cases & Mean & Standard Deviation \\
\hline \multirow{3}{*}{ St. Andrew's } & Male & 1234 & 30.0 & 8.73 \\
Hospital & Female & 255 & 29.4 & 9.54 \\
& Total & 1489 & 29.9 & 8.88 \\
& Male & 330 & 30.5 & 8.51 \\
Kasungu & Female & 107 & 32.7 & 10.0 \\
District Hospital & Total & 437 & 31.0 & 8.94 \\
& Male & 1564 & 30.1 & 8.68 \\
Combined & Female & 362 & 30.3 & 9.78 \\
& Total & 1926 & 30.2 & 8.90 \\
\hline
\end{tabular}

Table 3. Average hemoglobin concentration $(\mathrm{g} / \mathrm{dL})$ of male and female blood donors $(\mathrm{n}=$ 1558).

\begin{tabular}{ccccc}
\hline Hospital & Sex Group & Applicable Cases & Mean & Standard Deviation \\
\hline St. Andrew's & Male & 1014 & 15.1 & 4.19 \\
Hospital & Female & 216 & 13.4 & 1.96 \\
Kasungu & Male & 253 & 15.1 & 1.29 \\
District Hospital & Female & 75 & 13.7 & 1.53 \\
& Male & 1267 & 15.1 & 3.80 \\
Combined & Female & 291 & 13.5 & 1.86 \\
\hline
\end{tabular}


Table 4. Blood group distribution $(\mathrm{n}=2082)$.

\begin{tabular}{cccccc}
\hline Hospital & ABO Blood Group & Rh+ & Rh- & Not Done & Total \\
\hline \multirow{3}{*}{ St. Andrew's } & A & 241 & 51 & 4 & 296 \\
Hospital & B & 174 & 148 & 0 & 322 \\
& AB & 9 & 45 & 0 & 54 \\
Kasungu & O & 811 & 163 & 0 & 974 \\
District Hospital & A & 89 & 0 & 3 & 92 \\
& B & 93 & 1 & 3 & 97 \\
& AB & 11 & 0 & 0 & 11 \\
Combined & O & 230 & 0 & 6 & 236 \\
& A & 330 & 51 & 7 & 388 \\
& B & 267 & 149 & 3 & 419 \\
& AB & 20 & 45 & 0 & 65 \\
& O & 1041 & 163 & 6 & 1210 \\
\hline
\end{tabular}

Table 5. Directed blood donation eligibility $(n=1977)$.

\begin{tabular}{cccccc}
\hline Hospital & Sex Group & Accepted & Rejected & Total & Acceptance Rate (\%) \\
\hline \multirow{2}{*}{$\begin{array}{c}\text { St. Andrew's Hos- } \\
\text { pital }\end{array}$} & Male & 833 & 430 & 1263 & 66.0 \\
& Female & 177 & 98 & 275 & 64.4 \\
& Total & 1010 & 528 & 1538 & 65.7 \\
Kasungu & Male & 212 & 120 & 332 & 63.9 \\
District Hospital & Female & 59 & 48 & 107 & 55.1 \\
& Total & 271 & 168 & 439 & 61.7 \\
& Male & 1045 & 550 & 1595 & 65.5 \\
Combined & Female & 236 & 146 & 382 & 61.8 \\
& Total & 1281 & 696 & 1977 & 64.8
\end{tabular}

Table 6. Distribution of TTIs among directed blood donations $(\mathrm{n}=1982)$.

\begin{tabular}{ccccc}
\hline Hospital & TTI & Positive & Negative & Not Done \\
\hline \multirow{2}{*}{ St. Andrew's Hospital } & HIV & 16 & 1250 & 273 \\
& Hepatitis B & 35 & 1227 & 277 \\
& Hepatitis C & 6 & 426 & 1107 \\
& Syphilis & 14 & 1243 & 282 \\
& Malaria & 199 & 1076 & 264 \\
& HIV & 13 & 361 & 69 \\
& Hepatitis B & 17 & 358 & 68 \\
& Hepatitis C & 8 & 337 & 98 \\
& Syphilis & 5 & 372 & 66 \\
& Malaria & 97 & 224 & 122 \\
& HIV & 29 & 1640 & 342 \\
& Hepatitis B & 52 & 1637 & 345 \\
& Hepatitis C & 14 & 777 & 1205 \\
& Syphilis & 19 & 1634 & 348 \\
& Malaria & 296 & 1596 & 386 \\
\hline
\end{tabular}




\section{Discussion}

To the best of our knowledge, this is the first analysis of directed blood donations in Malawi. As an underdeveloped country, Malawi lacks many sources of reliable data concerning blood transfusions in general. We have characterized 2134 directed donations of two hospitals from the Kasungu district with respect to sex, age, hemoglobin concentration, blood group, and presence of transfusion-transmissible infections. The infections tested were HIV, viral hepatitis B and $\mathrm{C}$, syphilis, and malaria.

While the male to female ratio in Malawi is 0.99 from ages 15 - 54, we have found that directed blood donations of the Kasungu district constituted of mostly males [7]. This disproportion might stem from the fact that during times of emergency, males are socially expected to volunteer. Unlike allogeneic blood donations handled by MBTS, hospital directed blood donations are relatively unexpected and urgently collected. This may add an additional level of stress or fear that males may be better equipped to handle. Furthermore, both male and female donors averaged to be 30 years of age. The data are consistent with Malawi's young age demographics: $20.5 \%$ of the population falls between $15-24$ years of age, and $27.3 \%$ fall between 25 - 54 years [7]. Average hemoglobin concentrations of donations show healthy levels for both male and female donors [8].

The $\mathrm{ABO}$ antigen frequencies of directed donations of both hospitals of the Kasungu district are similar to those of the Malawian blood donor population, which show a $20.8 \%, 4.0 \%, 20.2 \%$, and $54.6 \%$ distribution for $\mathrm{A}, \mathrm{AB}, \mathrm{B}$, and $\mathrm{O}$ antigens respectively. This distribution is also similar to the relative $\mathrm{ABO}$ antigen frequencies of the Black population in the United States. Caucasians of the United States, on the other hand, maintain a contrasting distribution of $40 \%$, $4 \%, 11 \%$, and $45 \%$ for $\mathrm{A}, \mathrm{AB}, \mathrm{B}$, and $\mathrm{O}$ antigens respectively. The similarity between Malawian blood donors and Kasungu emergency blood donors suggests that one may find a consistent $\mathrm{ABO}$ antigen distribution among the various districts of Malawi. Nonetheless, one noticeable difference between directed donations of Kasungu and allogeneic blood donations of Malawi is the prevalence of the $\mathrm{RhD}$ factor among donors. The $\mathrm{RhD}$ factor is prevalent in over $95 \%$ of Malawi's blood donor and patient population, yet our data indicate that the RhD factor was only present in $80 \%$ of directed donations [6].

When hospitals acquire blood donations independently of MTBS, testing for transfusion-transmissible infections is less thorough. However, about $1 / 3$ of directed donations still did not meet safety requirements to be utilized, largely due to the prevalence of TTIs. Those who are diagnosed with TTIs are ineligible to donate, so individuals who are aware that they have a TTI do not volunteer to donate. The TTI incidence among blood donations reveals a systemic issue pervasive throughout underprivileged countries: a substantial portion of the population has undiagnosed diseases.

Although these findings appear to be robust, they should be interpreted lightly 
due to the limitations of our analysis. Limitations of this study include a lack of complete records for every parameter studied. This is indicated by the Not Done cases noted in Table 4 and Table 6. As a result, data must be interpreted with this in mind. Among the 2134 directed blood donations analyzed, the number of applicable cases varied depending on the analysis conducted due to a lack of sufficient data. Oftentimes, records were incomplete due to a lack of hospital resources. In addition, because the directed donation data received from Kasungu district hospital spanned only one month, it is less statistically significant than the data received from St. Andrew's hospital. Lastly, because hospital directed donation data is anonymous, we were unable to consider repeat donations.

\section{Conclusion}

In conclusion, this study characterizes direct blood donor demographics and draws attention to the depth of issues surrounding blood transfusion in Malawi. The practical implications of these findings relate to the potential improvement of blood transfusion services in Malawi.

\section{Acknowledgements}

The authors acknowledge the STEM Research Institute and Youth with Talents for sponsoring this medical project. We would like to thank staff from St. Andrew's hospital and Kasungu District Hospital for their advice and assistance throughout this study. Furthermore, we are thankful for the permission and opportunity to conduct a retrospective analysis on their hospital data.

\section{Conflicts of Interest}

The authors declare no conflicts of interest regarding the publication of this paper.

\section{References}

[1] Agarwal, R.K., Dhanya, R. and Parmar, L.G. (2015) A Study of the Noncompliance of Blood Banks on Safety and Quality Parameters in Blood Donation Camps in Bengaluru. Asian Journal of Transfusion Science, 9, 23-28. https://doi.org/10.4103/0973-6247.150942

[2] Dogbe, E.E. and Arthur, F. (2015) Diagnostic Accuracy of Blood Centers in the Screening of Blood Donors for Viral Markers. The Pan African Medical Journal, 20, 119. https://doi.org/10.11604/pamj.2015.20.119.5263

[3] Osaro, E. and Charles, A.T. (2011) The Challenges of Meeting the Blood Transfusion Requirements in Sub-Saharan Africa: The Need for the Development of Alternatives to Allogenic Blood. Journal of Blood Medicine, 2, 7-21. https://doi.org/10.2147/JBM.S17194

[4] Wilson, M.L., Walker, E.D. and Taylor, T. (2012) Malaria Elimination in Malawi: Research Needs in Highly Endemic, Poverty-Stricken Contexts. Acta Tropica, 121, 218-226. https://doi.org/10.1016/j.actatropica.2011.11.002

[5] American Red Cross (2018) Types of Blood Donations. 
http://www.redcrossblood.org/donating-blood/types-donations/autologous-and-dir ected

[6] Malawi Blood Transfusion Service, Give Blood, Save Lives. http://www.mbtsmalawi.com/

[7] Malawi Demographics Profile 2018. http://www.indexmundi.com/malawi/demographics_profile.html

[8] American Red Cross (2018) Donors Deferred for Low Hemoglobin. http://www.redcrossblood.org/learn-about-blood/iron-and-blood-donation/donors -deferred-low-hemoglobin 